\title{
Continuous electrocardiogram changes preceding phenotypic expression for 8 years in an athlete with hypertrophic cardiomyopathy: a case report
}

\author{
Dan Han ${ }^{1}$, Yan $\mathrm{Ji}^{1}$ and Hui $\operatorname{Tan}^{2^{*}}$
}

\begin{abstract}
Background: Hypertrophic cardiomyopathy is one of the most common causes of sudden cardiac death in young athletes. Performing, comparing, and monitoring serial electrocardiograms over time can help to detect potential cardiovascular diseases and to prevent malignant cardiac events in these populations.

Case presentation: A young Han Chinese male football player had abnormal electrocardiograms for 8 years without any subjective discomfort. Electrocardiograms revealed that T-wave inversions increased from $1 \mathrm{~mm}$ to a maximum of 5 $\mathrm{mm}$ on lead I and fluctuated around $5 \mathrm{~mm}$ on lead avL. Q-wave duration ranged from $40 \mathrm{~ms}$ to $60 \mathrm{~ms}$, its depth increased to a maximum of $8 \mathrm{~mm}$ and was much greater than $40 \%$ of the R waves in depth in $\mathrm{II}$, III, and avF leads. Echocardiography showed increasingly thickened interventricular septum from $10 \mathrm{~mm}$ to $13 \mathrm{~mm}$, enlarged left atrium and ventricle, and reduced left ventricular ejection fraction. Coronary angiography showed no distinct stenosis. Emission computed tomography revealed mild myocardial ischemia of the left ventricular inferior wall. These unusual electrocardiogram manifestations were initially regarded as benign alterations of a highly trained athlete. Upon reviewing the clinical information and the newest criteria for electrocardiographic interpretation in athletes, hypertrophic cardiomyopathy was identified. The misreading of electrocardiograms is not uncommon, thus predisposing such patients to high susceptibility to exercise-induced sudden cardiac death.

Conclusions: We propose that abnormal electrocardiogram findings reveal the initial expression of underlying cardiac diseases such as hypertrophic cardiomyopathy, preceding the symptoms and signs by many years. Accordingly, early detection and continuous surveillance are important for athletes with such electrocardiogram patterns, and improvement of physicians' expertise is crucial.
\end{abstract}

Keywords: Hypertrophic cardiomyopathy, ECG alterations, Abnormal Q waves, T-wave inversion, Athlete

\section{Introduction}

Sudden cardiac death (SCD) is an important and emotionally charged public health issue $[1,2]$. Hypertrophic cardiomyopathy $(\mathrm{HCM})$ is the most frequent heart disease that causes SCD in the young population, especially in athletes during high-intensity training [3]. Athletes occasionally manifest with abnormal electrocardiogram (ECG) findings, many of which are usually considered as

\footnotetext{
* Correspondence: shanshantan666@126.com

Department of Rehabilitation Medicine, First Affiliated Hospital of Xi'an Jiaotong University, No. 277 Yanta West Road, Xi'an, Shaanxi 710061, People's Republic of China

Full list of author information is available at the end of the article
}

an inculpable presentation of cardiac structural remodeling in connection with intensive and systematic exercise [4]. However, in a minority of athletes, ECGs might be obviously abnormal and erratic, indicating the initial presence of a potential cardiac disease such as HCM, even when there is no visible structural heart condition [5]. Progressively abnormal ECG patterns may represent the initial, subtle expressions of cardiac diseases with long-lasting negative clinical outcomes [3]. In young athletes, the differential diagnosis between nonpathological alterations of cardiac structure related to training (generally termed "athlete's heart") and certain cardiac diseases with a risk of

(C) The Author(s). 2019 Open Access This article is distributed under the terms of the Creative Commons Attribution 4.0 International License (http://creativecommons.org/licenses/by/4.0/), which permits unrestricted use, distribution, and 
SCD remains a particularly significant clinical problem [6]. We report a case of a young athlete who was diagnosed as HCM without any discomfort or obvious alterations of visible heart morphology but manifested gradually aggravated abnormal Q waves and T-wave inversions (TWIs) on ECGs over the course of 8 years. This case report reveals that abnormal ECG alterations may precede the symptoms and signs of HCM for many years, and it further supports the fact that markedly aberrant cardiac electrical activity may represent the subtle expression of an underlying cardiac disorder that may not become evident until many years later. Accordingly, early detection and continuous surveillance are important for athletes with such ECG patterns, and improvements in physicians' expertise are crucial.

\section{Case presentation}

A 35-year-old Han Chinese male football player presented with abnormal ECGs for 8 years without any evident subjective discomfort. The patient recently complained about slight exertional dyspnea with reduced sport/physical tolerance and was admitted to our hospital. This patient had been employed as a professional football player from the age of 10 years and had been a physical education teacher from the age of 26 years. He was a longtime local resident and never went to any affected areas (areas with high prevalence of infectious diseases). He reported being formerly healthy without any medical histories or current comorbidities, and he reported taking no medications. He has smoked 20 cigarettes per day for 7 years and consumed alcohol for 10 years at 100 to $250 \mathrm{~g}$ per day. His parents were healthy, and his family history was unremarkable. His physical examination revealed no abnormal findings. His body temperature was $36.5^{\circ} \mathrm{C}$, blood pressure was $121 / 73$ $\mathrm{mmHg}$, respiratory rate was 18 breaths/min, pulse was $69 / \mathrm{min}$, heart rate was 70 beats/min, and reflexes were normal. He had no pathology reflex, and his body mass index was $22.81 \mathrm{~kg} / \mathrm{m}^{2}$. Laboratory evaluation revealed slightly elevated cardiac troponin T level of $0.017 \mathrm{ng} / \mathrm{ml}$, $\mathrm{N}$-terminal probrain natriuretic peptide level of 291.80 $\mathrm{pg} / \mathrm{ml}$, and C-reactive protein level of $0.40 \mathrm{mg} / \mathrm{L}$. The patient's blood lipid levels, liver function, and renal function were within the normal range with glutamic oxaloacetic transaminase level of $23 \mathrm{U} / \mathrm{L}$, glutamic-pyruvic transaminase level of $31 \mathrm{U} / \mathrm{L}$, alkaline phosphatase level of $84 \mathrm{U} / \mathrm{L}$, total protein level of $67.9 \mathrm{~g} / \mathrm{L}$, albumin level of $41 \mathrm{~g} / \mathrm{L}$, globulin level of $26.9 \mathrm{~g} / \mathrm{L}$, total cholesterol level of $4.01 \mathrm{mmol} / \mathrm{L}$, triglyceride level of $1.42 \mathrm{mmol} / \mathrm{L}$, high-density lipoprotein level of $1.08 \mathrm{mmol} / \mathrm{L}$, low-density lipoprotein level of $2.14 \mathrm{mmol} / \mathrm{L}$, uric acid level of $353 \mu \mathrm{mol} / \mathrm{L}$, epidermal growth factor receptor level of $105.48 \mathrm{ml} / \mathrm{min} / 1.73 \mathrm{~m}^{2}$; serum $\mathrm{K}^{+}$level of 4.05 $\mathrm{mmol} / \mathrm{L}$, serum $\mathrm{Ca}^{2+}$ level of $2.16 \mathrm{mmol} / \mathrm{L}$, serum $\mathrm{Mg}^{2+}$ level of $0.88 \mathrm{mmol} / \mathrm{L}$, and serum $\mathrm{Na}^{+}$level of $141 \mathrm{mmol} /$
L. The results of routine blood test and urinalysis were negative, thyroid function was normal, and microorganisms were not detected. Chest radiography showed an apparently normal morphology of the heart and lungs (Fig. 1). ECGs revealed progressively deepened and widened Q waves on the II, III, and avF leads and contiguous TWIs on the I and avL leads (Fig. 2, Table 1). Echocardiography revealed an increasingly thickened interventricular septum from $10 \mathrm{~mm}$ to $13 \mathrm{~mm}$, an enlarged left atrium and ventricle, and a reduced left ventricular ejection fraction from $73 \%$ to $63 \%$ (Fig. 3). Coronary angiography (CAG) was performed and showed no distinct stenosis. Emission computed tomography (ECT) revealed mild myocardial ischemia of the left ventricular inferior wall (Fig. 4). All of these clinical tests supported the diagnosis of HCM, which became gradually evident with time. For further identification, we proposed other examination techniques for this patient, including cardiac magnetic resonance imaging (CMRI) to better evaluate the left ventricular wall thickness and to identify potential areas of myocardial fibrosis, Holter monitor recordings and an exercise test to evaluate possible "dynamic" changes of repolarization abnormalities, as well as genetic testing. However, the patient refused all of these suggestions and was discharged. In the subsequent follow-up visits at 1 month, 3 months, and 6 months after discharge, the patient showed poor compliance and was eventually lost to follow-up.

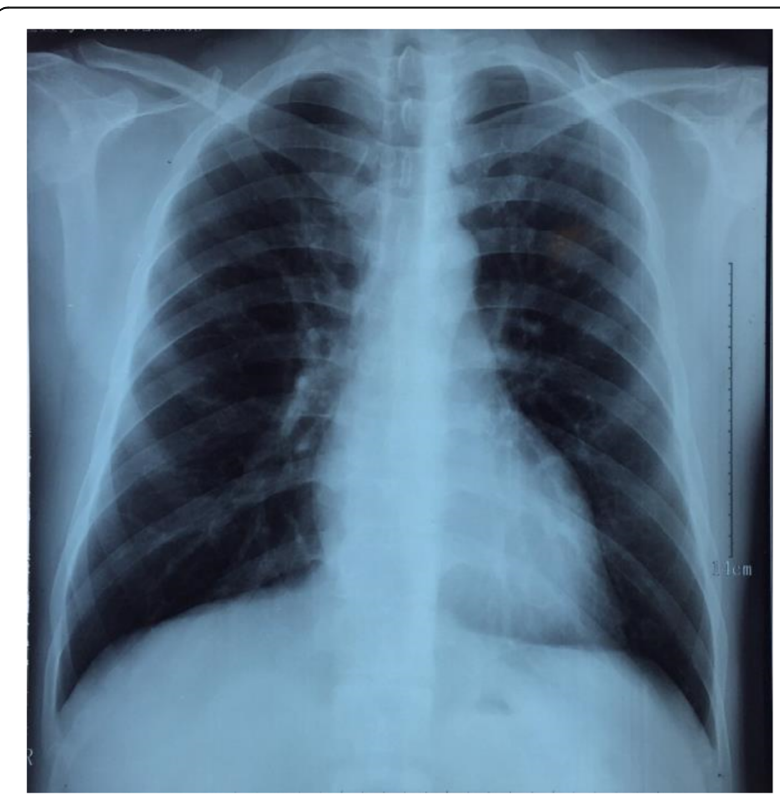

Fig. 1 Chest radiography showed seemingly normal structures of heart and lungs 


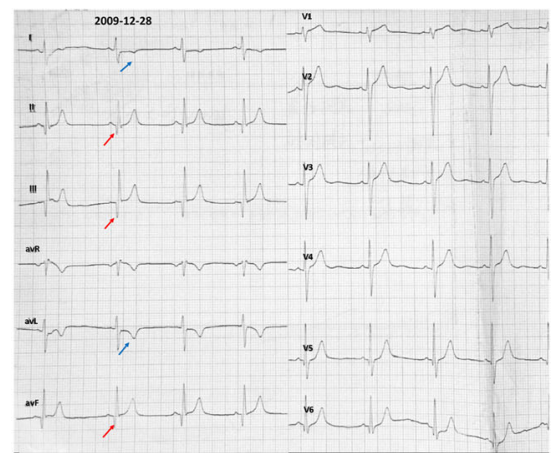

A

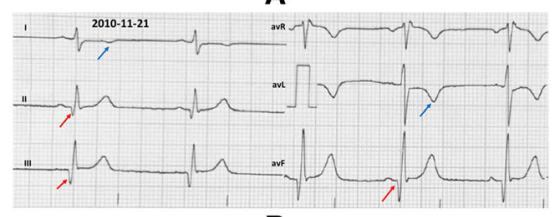

B
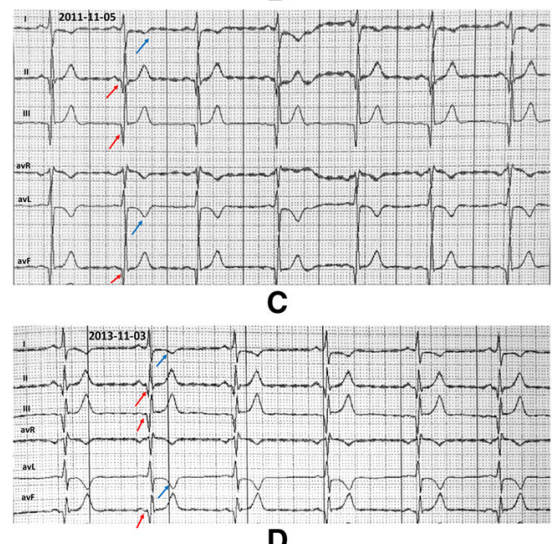

D

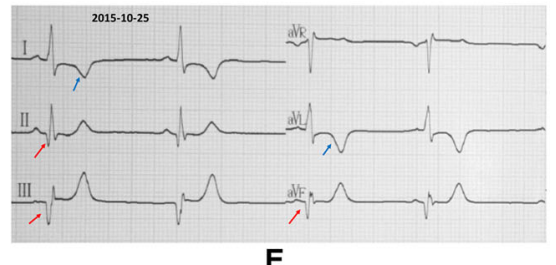

E

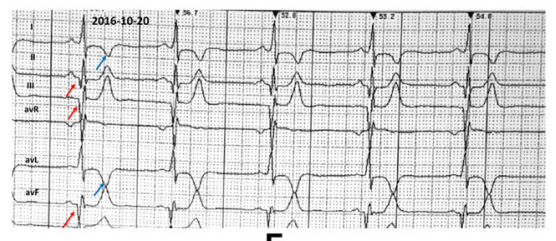

$\mathbf{F}$

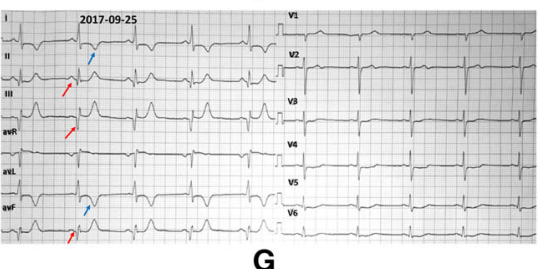

Fig. 2 Electrocardiogram tracings recorded in 2009 (a), 2010 (b) 2011 (c), 2013 (d), 2015 (e), 2016 (f), and 2017 (g) indicated progressively deepened and widened Q waves (red arrowheads) and persistent T-wave inversion (blue arrowheads)

\section{Discussion}

Our patient manifested with abnormal ECGs, including progressively deepened and widened $\mathrm{Q}$ waves on the II, III, avF leads, and persistent TWIs on the I, avL leads. TWIs increased from $1 \mathrm{~mm}$ to a maximum of $5 \mathrm{~mm}$ on lead I and fluctuated approximately $5 \mathrm{~mm}$ on lead avL. The Q-wave duration ranged from $40 \mathrm{~ms}$ to $60 \mathrm{~ms}$, and the depth increased to a maximum of $8 \mathrm{~mm}$, which was much greater than $40 \%$ of the R-wave depth in the II, III, avF leads. Echocardiography showed an increasingly thickened interventricular septum from $10 \mathrm{~mm}$ to $13 \mathrm{~mm}$, which is considered to be in the gray zone, and an enlarged left atrium and ventricle with reduced left ventricular ejection fraction from $73 \%$ to $63 \%$. CAG revealed no distinct stenosis. ECT showed mild myocardial ischemia of the left ventricular inferior wall, which may present as pathological Q waves on ECGs. These alterations highly suggested the potential condition of HCM for this patient; thus, further examinations were recommended to confirm the diagnosis. Participation in competitive athletics was restricted as a timely prophylactic for longer survival. Pharmacological agents (for example, $\beta$-blockers) to control cardiac-related symptoms or ventricular arrhythmias and prophylactic implantable cardioverter-defibrillator were not applicable for this patient [7]. These ECG manifestations were initially regarded as benign alterations in this patient due to a shortage of physician expertise. This kind of phenomenon is not uncommon; therefore, an urgent need exists for physician

Table 1 Electrocardiogram measurement over 8 years

\begin{tabular}{|c|c|c|c|c|c|c|c|c|c|c|c|}
\hline \multirow[t]{2}{*}{ Date } & \multicolumn{2}{|c|}{$\begin{array}{l}\text { TWls } \\
\text { depth } \\
(\mathrm{mm})\end{array}$} & \multicolumn{3}{|c|}{$\begin{array}{l}\text { Q-wave } \\
\text { duration } \\
\text { (ms) }\end{array}$} & \multicolumn{3}{|c|}{$\begin{array}{l}\text { Q-wave } \\
\text { depth } \\
(\mathrm{mm})\end{array}$} & \multicolumn{3}{|c|}{$\mathrm{Q} / \mathrm{R}(\%)$} \\
\hline & I & $\overline{\mathrm{avL}}$ & $\|$ & III & $\overline{a v F}$ & $\|$ & III & $\overline{a v F}$ & $\|$ & III & $\overline{a v F}$ \\
\hline $28 / 12 / 2009$ & 1 & 5 & 40 & 40 & 40 & 4 & 6 & 4 & 40 & 43 & 33 \\
\hline $1 / 11 / 2010$ & 1 & 4 & 40 & 40 & 40 & 2 & 3.5 & 5.1 & 40 & 50 & 43 \\
\hline $55 / 11 / 2011$ & 2 & 4 & 40 & 40 & 40 & 6 & 8 & 5 & 60 & 67 & 42 \\
\hline $03 / 11 / 2013$ & 2.5 & 5 & 40 & 50 & 50 & 4 & 6 & 4 & 67 & 100 & 100 \\
\hline 25/10/2015 & 5 & 5 & 40 & 50 & 40 & 3.5 & 5 & 4 & 58 & 125 & 200 \\
\hline 20/10/2016 & 3.5 & 6 & 40 & 60 & 50 & 4 & 7 & 5 & 80 & 233 & 200 \\
\hline $25 / 09 / 2017$ & 3 & 5 & 40 & 50 & 40 & 3 & 5 & 4 & 60 & 100 & 133 \\
\hline
\end{tabular}

TWIs T-wave inversions 


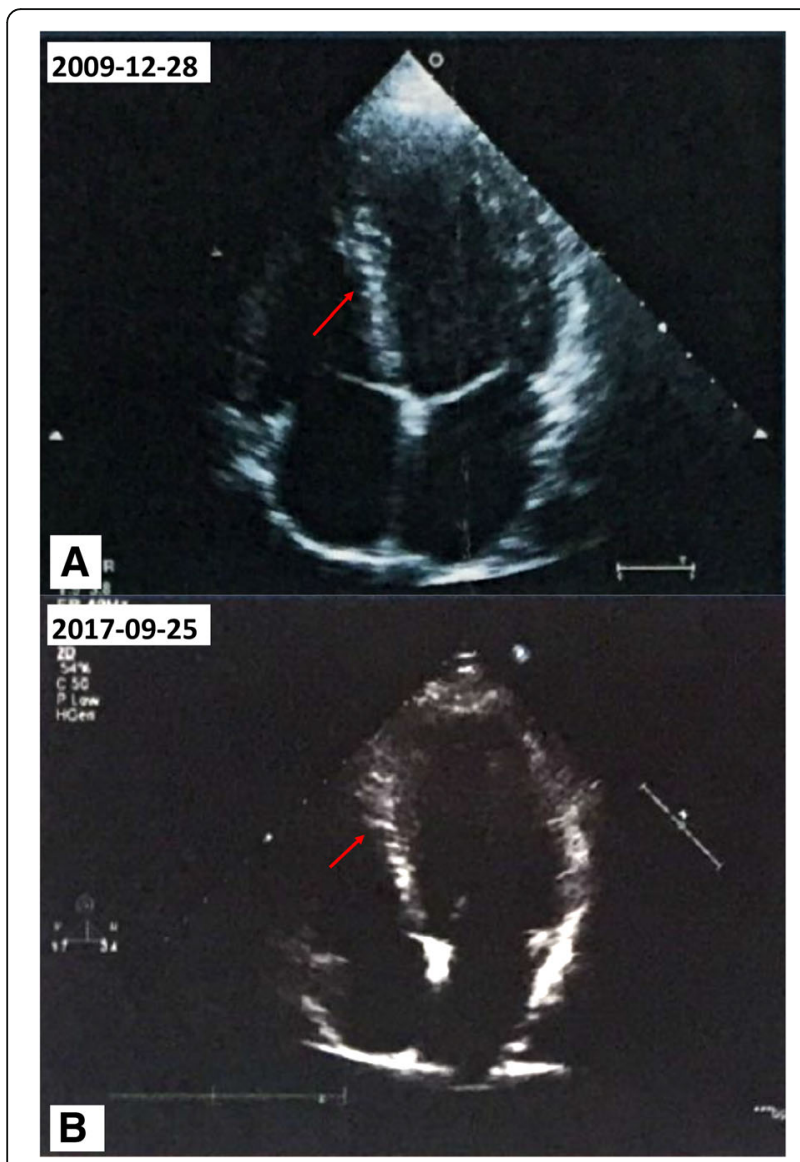

Fig. 3 Echocardiography showed increasingly thickened interventricular septum from $10 \mathrm{~mm}$ (a) to $13 \mathrm{~mm}$ (b) (red arrowheads), enlarged left atrium and ventricle, and reduced left ventricular diastolic function education on modern ECG interpretation that distinguishes normal physiological adaptations in athletes from distinctly abnormal findings that are suggestive of underlying pathology.

The international consensus standards for ECG interpretation in athletes that suggest the potential for HCM include TWI $\geq 1 \mathrm{~mm}$ in depth in two or more contiguous leads, excluding III, aVR, and V1; and pathological Q waves $\geq 40 \mathrm{~ms}$ in duration and/or $\geq 3$ $\mathrm{mm}$ in depth and/or $\mathrm{Q} / \mathrm{R} \geq 25 \%$ in at least two contiguous leads except for III and aVR [8,9]. Pathological Q waves are the most common ECG findings associated with HCM and present in $32 \%$ to $42 \%$ of patients, especially those who exhibit an unusual pattern of ventricular hypertrophy [10]. The mechanism underlying HCM-related $\mathrm{Q}$ waves is an abnormal electrical activity of the hypertrophic ventricular septum [11]. Pathological studies revealed that abnormal $\mathrm{Q}$ waves that formed by the loss of electrical forces due to transmural myocardial fibrosis resembled those associated with myocardial infarction [12]. Another mechanism is that the resultant initial QRS vector alters its direction due to enhanced electrical forces of asymmetrical hypertrophy of the basal ventricular septum and/or basal left ventricular free wall, which is unopposed by apical electrical forces [13].

TWI indicates abnormal repolarization of the ventricular myocardium. In a cohort of young (aged $<35$ years) asymptomatic patients with confirmed HCM, $62 \%$ exhibited abnormal TWI [10]. In patients with HCM without evident symptoms, the prevalence of abnormal TWI was reported as 80\% [14]. More recently, the prevalence of abnormal TWI among athletes with newly diagnosed HCM was reportedly in excess of $90 \%$ [15]. TWI $\geq 1 \mathrm{~mm}$ on at least two contiguous leads except III, aVR, and V1 should be carefully assessed and should prompt further examinations, such as echocardiography, CMRI, an exercise ECG test, and a minimum of $24 \mathrm{~h}$ of ECG monitoring for underlying cardiac diseases [9].

\section{Conclusion}

In our patient, abnormal ECG findings indicated that the initial expression of underlying cardiac diseases, such as HCM, preceded the signs and symptoms for many years. Accordingly, early detection and continuous surveillance are important for athletes who display such ECG patterns; moreover, improvements in physician expertise are crucial.

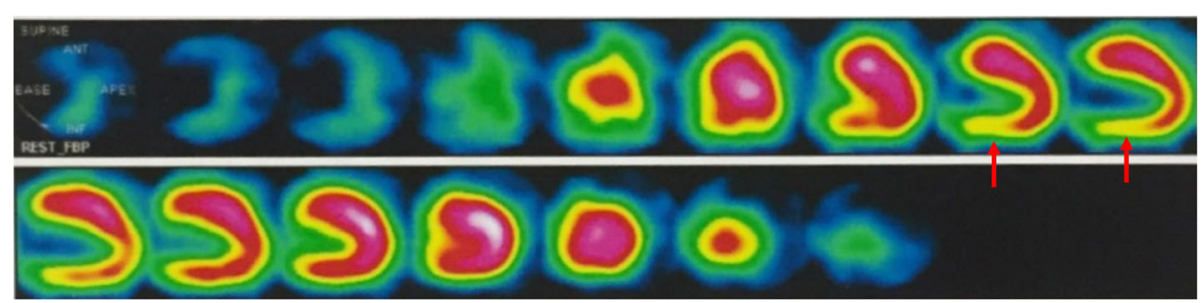

Fig. 4 Emission computed tomography revealed mild myocardial ischemia of the left ventricular inferior wall (red arrowheads) 


\section{Acknowledgements}

We really appreciate the patient's cooperation in this study.

\section{Availability of data and materials}

All data generated or analyzed during this study are original.

\section{Congress}

Accepted by 04/15-17/2018 European Cardiac Arrhythmia Society (ECAS), Paris.

\section{Authors' contributions}

$\mathrm{DH}$ collected the data and wrote the draft of the manuscript. YJ and HT revised the manuscript. All authors read and approved the final manuscript.

\section{Ethics approval and consent to participate}

This case report was approved by the First Affiliated Hospital of Xi'an Jiaotong University ethics committee and carried out in conformance with the principles of the Declaration of Helsinki. Both verbal and written informed consent were obtained from the patient before submission.

\section{Consent for publication}

Written informed consent was obtained from the patient for publication of this case report and any accompanying images. A copy of the written consent is available for review by the Editor-in-Chief of this journal.

\section{Competing interests}

The authors declare that they have no competing interests.

\section{Publisher's Note}

Springer Nature remains neutral with regard to jurisdictional claims in published maps and institutional affiliations.

\section{Author details}

'Department of Cardiovascular Medicine, First Affiliated Hospital of Xi'an Jiaotong University, No. 277 Yanta West Road, Xi'an, Shaanxi 710061, People's Republic of China. ${ }^{2}$ Department of Rehabilitation Medicine, First Affiliated Hospital of Xi'an Jiaotong University, No. 277 Yanta West Road, Xi'an, Shaanxi 710061, People's Republic of China.

Received: 20 July 2018 Accepted: 25 January 2019

Published online: 21 March 2019

\section{References}

1. Thompson PD, Franklin BA, Balady GJ, Blair SN, Corrado D, Estes NA 3rd, Fulton JE, Gordon NF, Haskell WL, Link MS, et al. Exercise and acute cardiovascular events placing the risks into perspective: a scientific statement from the American Heart Association Council on Nutrition, Physical Activity, and Metabolism and the Council on Clinical Cardiology. Circulation. 2007; 115:2358-68.

2. Link MS, Estes NA 3rd. Sudden cardiac death in the athlete: bridging the gaps between evidence, policy, and practice. Circulation. 2012;125:2511-6.

3. Pelliccia A, Di Paolo FM, Quattrini FM, Basso C, Culasso F, Popoli G, De Luca R, Spataro A, Biffi A, Thiene G, Maron BJ. Outcomes in athletes with marked ECG repolarization abnormalities. N Engl J Med. 2008;358:152-61.

4. Maron BJ, Pelliccia A. The heart of trained athletes: cardiac remodeling and the risks of sports, including sudden death. Circulation. 2006;114:1633-44.

5. Maron BJ, Pelliccia A, Spirito P. Cardiac disease in young trained athletes. Insights into methods for distinguishing athlete's heart from structural heart disease, with particular emphasis on hypertrophic cardiomyopathy. Circulation. 1995;91:1596-601

6. Huston TP, Puffer JC, Rodney WM. The athletic heart syndrome. N Engl J Med. 1985;313:24-32.

7. Mitten MJ, Zipes DP, Maron BJ, Bryant WJ. Eligibility and disqualification recommendations for competitive athletes with cardiovascular abnormalities: Task Force 15: legal aspects of medical eligibility and disqualification recommendations: a scientific statement from the American Heart Association and American College of Cardiology. Circulation. 2015; 132:e346-9.

8. Elliott PM, Anastasakis A, Borger MA, Borggrefe M, Cecchi F, Charron P, Hagege AA, Lafont A, Limongelli G, Mahrholdt H, et al. 2014 ESC guidelines on diagnosis and management of hypertrophic cardiomyopathy: the Task
Force for the Diagnosis and Management of Hypertrophic Cardiomyopathy of the European Society of Cardiology (ESC). Eur Heart J. 2014;35:2733-79.

9. Drezner JA, Sharma S, Baggish A, Papadakis M, Wilson MG, Prutkin JM, Gerche A, Ackerman MJ, Borjesson M, Salerno JC, et al. International criteria for electrocardiographic interpretation in athletes: consensus statement. $\mathrm{Br}$ 」 Sports Med. 2017;51:704-31.

10. Rowin EJ, Maron BJ, Appelbaum E, Link MS, Gibson CM, Lesser JR, Haas TS, Udelson JE, Manning WJ, Maron MS. Significance of false negative electrocardiograms in preparticipation screening of athletes for hypertrophic cardiomyopathy. Am J Cardiol. 2012;110:1027-32.

11. Maron BJ, Wolfson JK, Ciro E, Spirito P. Relation of electrocardiographic abnormalities and patterns of left ventricular hypertrophy identified by 2 dimensional echocardiography in patients with hypertrophic cardiomyopathy. Am J Cardiol. 1983;51:189-94.

12. Maron BJ, Epstein SE, Roberts WC. Hypertrophic cardiomyopathy and transmural myocardial infarction without significant atherosclerosis of the extramural coronary arteries. Am J Cardiol. 1979;43:1086-102.

13. Koga Y, Yamaga A, Hiyamuta K, Ikeda H, Toshima H. Mechanisms of abnormal Q waves in hypertrophic cardiomyopathy assessed by intracoronary electrocardiography. J Cardiovasc Electrophysiol. 2004;15: 1402-8

14. Chen X, Zhao T, Lu M, Yin G, Xiangli W, Jiang S, Prasad S, Zhao S. The relationship between electrocardiographic changes and CMR features in asymptomatic or mildly symptomatic patients with hypertrophic cardiomyopathy. Int J Cardiovasc Imaging. 2014;30(Suppl 1):55-63.

15. Sheikh N, Papadakis M, Schnell F, Panoulas V, Malhotra A, Wilson M, Carre F, Sharma S. Clinical profile of athletes with hypertrophic cardiomyopathy. Circ Cardiovasc Imaging. 2015;8:e003454.
Ready to submit your research? Choose BMC and benefit from:

- fast, convenient online submission

- thorough peer review by experienced researchers in your field

- rapid publication on acceptance

- support for research data, including large and complex data types

- gold Open Access which fosters wider collaboration and increased citations

- maximum visibility for your research: over 100M website views per year

At $\mathrm{BMC}$, research is always in progress.

Learn more biomedcentral.com/submissions 